\title{
Nutritional ocular diseases and their association with diarrhoea in Matlab, Bangladesh
}

\author{
BY MOSLEM UDDIN KHAN, MD. EMDADUL HAQUE \\ AND MATIAR RAHMAN KHAN \\ International Centre for Diarrhoeal Disease Research, Bangladesh, GPO Box 128, \\ Dhaka-2, Bangladesh
}

(Received 11 October 1983 - Accepted 9 January 1984)

\begin{abstract}
1. The prevalence of visual defects, especially from causes associated with nutritional deficiencies, and their relation to diarrhoea in rural Bangladesh have been studied. A trained physician and a team of health workers examined visual defects in 149 villages, with a total population of 182976 .

2. According to WHO classification, night blindness $(\mathrm{XN})$ was found in only 0.03 persons $/ 1000$ population and 0.04 were found to have conjunctival xerosis (XIA) and Bitot's spot (XIB). Corneal xerosis (X2, X3A, X3B) also was found in 0.04 persons $/ 1000$. Night blindness combined with conjunctival xerosis and Bitot's spot $(\mathrm{XN}+\mathrm{XIA}+\mathrm{XIB})$ was present in 1.69 persons/1000 and all combined stages of active xerophthalmia were seen in 0.06 persons $/ 1000$. Xerophthalmia prevailed up to age 19 years. Males had a significantly higher (2.9) incidence/1000 than did females (1-2).

3. The total rate of keratomalacial scar for all ages was 0.31 persons $/ 1000$, while corneal opacity from other causes was seen in $2 \cdot 25$ persons/ 1000 population.

4. More than 2.06 persons/1000 had ocular manifestations of one or more vitamin A deficiencies, while 4.47 persons $/ 1000$ had other ocular diseases, except for cataracts.

5 . Only $12.0 \%$ of all the corneal scars (XS) were due to keratomalacia.

6. History of night blindness is a good indicator of vitamin A deficiency. In $96 \%$ of cases, night blindness was associated with conjunctival xerosis and Bitot's spot $(\mathrm{XN}+\mathrm{XIA}+\mathrm{XIB})$.

7. The onset of approximately $86 \%$ of cases of corneal xerosis $(\mathrm{X} 2, \mathrm{X} 3 \mathrm{~A}, \mathrm{X} 3 \mathrm{~B})$ and night blindness associated with conjunctival xerosis and Bitot's spot $(X N+X I A+X I B)$ was related to diarrhoea.
\end{abstract}

Vitamin A deficiency and excess diarrhoea diseases are both common in developing countries. Sommer et al. (1981) found that, in Indonesia, between two and five pre-school children per 1000 had nutritional corneal lesions, and fifty-five per 1000 had conjunctival xerosis (XIA) plus Bitot's spot (XIB) with a history of night blindness (XN; Sommer et al. 1978). It has been reported by the Institute of Nutrition and Food Science, University of Dhaka (1977), that in $90 \%$ of families in Bangladesh the intake of vitamin $A$ is less than $70 \%$ of that required, and $5 \%$ of all children suffer from night blindness. Brown et al. (1981) found that $24 \%$ of protein-energy malnutrition cases admitted to the nutritional unit in Dhaka had nutritional corneal disease. Swaminathan et al. (1970) of India found that $1.7 \%$ of children under 6 years had keratomalacia. However, Horntino et al. (1978) found that $4.5 \%$ of children studied in the Philippines had xerophthalmia. McLaren (1970) estimated that xerophthalmia caused blindness in 100000 children annually, and it is thought that this number may be higher at present.

According to H. G. D. Mahler (WHO Day message, 1976, unpublished), two-thirds of the world's ten million cases of blindness are preventable. Bangladesh is fortunate because two of the most important causes of blindness, trachoma and river blindness (G. B. Bietti and F. Akin, WHO Day message, 1976, unpublished), are absent. However, Bangladesh faces the problems of childhood malnutrition and those arising from three to six annual episodes of diarrhoeal diseases per child (Black et al. 1980) which may lead to blindness. Bhar et al. (1982) recently found in Nigeria that, among people with impaired vision, nearly $20 \%$ had a corneal lesion. The former Cholera Research Laboratory (now the International 
Table 1. Details of subjects examined in the population of rural Matlab, Bangladesh

\begin{tabular}{|c|c|c|c|c|c|}
\hline & \multicolumn{3}{|c|}{ Age groups (years) } & \multirow[b]{2}{*}{ Total } & \multirow{2}{*}{$\begin{array}{c}\text { Percentage } \\
\text { of total }\end{array}$} \\
\hline & $0-6$ & $7-19$ & $20+$ & & \\
\hline${ }_{0}^{*}$ Patients & 108 & 206 & 366 & $680^{*}$ & 56.9 \\
\hline 3 Population & 20385 & 30923 & 41104 & 92412 & $50 \cdot 5$ \\
\hline Patients & 61 & 86 & 368 & $515^{*}$ & $43 \cdot 1$ \\
\hline$q$ Population & 18735 & 30335 & 41494 & 90564 & $49 \cdot 5$ \\
\hline Total cases & 169 & 292 & 734 & 1195 & \\
\hline Total population & 39120 & 61258 & 82598 & 182976 & \\
\hline
\end{tabular}

* Mean values for males and females were significantly different: $P<0.01$.

Centre for Diarrhoeal Disease Research, Bangladesh) found that blindness occurred among children as young as 5-9 years (M. U. Khan and J. Chakraborty, unpublished results). Although only $5.6 \%$ of the total Bangladesh population was aged 60 years or over, $52 \%$ of all blind people belonged to this age group (M. U. Khan, unpublished results). Approximately 7-8 years ago the prevalence of night blindness and corneal xerosis was 1.5 and $0.15 \%$ respectively in Bangladesh (Rahman, 1980). Nigar (1981) found an association between measles, diarrhoea and xerophthalmia in rural Bangladesh.

However, the role of diarrhoea in precipitating vitamin A deficiency-related ocular diseases has not been adequately studied. Moreover, after the countrywide distribution of vitamin A capsules to children, the prevalence of nutritional ocular diseases has not been studied in Bangladesh. Therefore, to document the role of diarrhoea in developing xerophthalmia and the current prevalence rates of xerophthalmia we conducted a prospective study in a known population from rural Matlab, Bangladesh.

\section{MATERIALS AND METHODS}

The study was conducted during 1981, in 149 villages that comprised the ICDDR, B Matlab Demographic Surveillance Area. The area's population at the time was 182976, with 92412 males and 90564 females. The census was kept up to date by regular visits (D'Souza, 1981). Every household was visited by a local field assistant $1 \mathrm{~d}$ before the eye examination. Anyone having an eye complaint was advised to go the next day to a well-known pre-selected house in the same village, for an eye examination. Children were accompanied by parents, blind people by a family member, and some people were unaccompanied. In all, 680 male and 515 female patients with visual complaints, excluding 1021 with cataracts, were recorded.

A physician, trained in an eye hospital, aided by a team of paramedical staff, examined and advised all patients who reported with eye complaints. Special attention was given to the identification of different grades of xerophthalmia, including night blindness $(\mathrm{XN})$, conjunctival xerosis (XIA), Bitot's spot (XIB) and corneal xerosis (X2, X3A, X3B). A detailed history of persistent diarrhoea, measles, smallpox, etc. occurring at the time of onset of an eye lesion, or within the preceding $30 \mathrm{~d}$, was obtained from the patient or from the patient's mother, and the results of the examination were recorded. An eye was designated 'blind' when the patient could neither read books nor count fingers beyond a distance of $1 \mathrm{~m}$. Xerosis of conjunctiva and cornea and keratomalacial scars were diagnosed and defined in accordance with the examples provided by D. S. McLaren and A. Sommer in WHO/USAID Joint Report (1976) and WHO/UNICEF Joint Report (1982), and the case histories of the patients. Night blindness was confirmed when patients, or their parents, 
Nutritional ocular diseases and diarrhoea

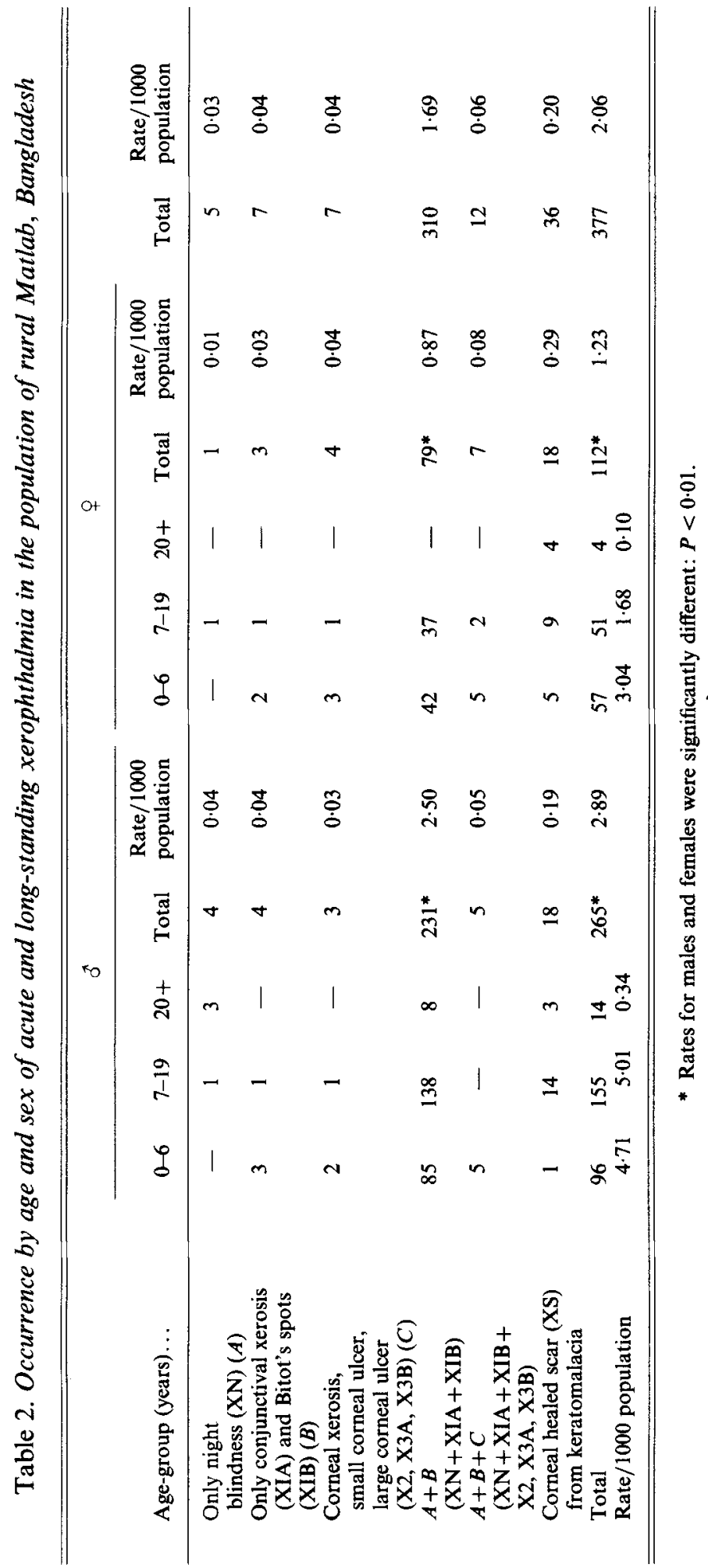


Table 3. Association of night blindness $(X N)$ with conjunctival xerosis $(X I A)$ and Bitot's spots $(X I B)$

\begin{tabular}{|c|c|c|c|c|c|c|c|c|c|c|}
\hline \multirow[b]{2}{*}{ Age-group (years)... } & \multicolumn{5}{|c|}{$\delta$} & \multicolumn{5}{|c|}{ q } \\
\hline & $0-6$ & $7-19$ & $20+$ & Total & $\%$ & $0-6$ & $7-19$ & $20+$ & Total & $\%$ \\
\hline $\begin{array}{l}\text { Only night } \\
\text { blindness }(\mathrm{XN})\end{array}$ & - & 1 & 3 & 4 & $1 \cdot 67$ & - & 1 & - & 1 & $1 \cdot 20$ \\
\hline $\begin{array}{l}\text { Only conjunctival } \\
\text { xerosis (XIA) and } \\
\text { Bitot's spots (XIB) }\end{array}$ & 3 & 1 & - & 4 & 1.67 & 2 & 1 & - & 3 & $3 \cdot 61$ \\
\hline $\begin{array}{l}\text { Night blindness, with } \\
\text { conjunctival xerosis } \\
\text { and Bitot's spots } \\
\text { (XN + XIA + XIB) }\end{array}$ & 85 & 138 & 8 & 231 & $96 \cdot 6$ & 42 & 37 & - & 79 & $95 \cdot 2$ \\
\hline Total & 88 & 140 & 11 & 239 & & 44 & 39 & - & 83 & \\
\hline Rate/ 1000 & $4 \cdot 3$ & $4 \cdot 5$ & $0 \cdot 26$ & $2 \cdot 6$ & & $2 \cdot 3$ & $1 \cdot 3$ & - & 0.9 & \\
\hline
\end{tabular}

Prevalence rates for males and females were not significantly different: $P>0 \cdot 05$.

complained that, in spite of having no sight problem during the daytime, they had difficulty seeing as well as others could during the hours of darkness. Retinitis pigmentosa was excluded by specific ophthalmoscopic findings. Individual cases have been classed according to single or multiple signs and symptoms present at the time of examination. Association of night blindness with conjunctival xerosis and Bitot's spot, and association of diarrhoea with xerophthalmia have been shown separately.

Cataract cases have been excluded from this analysis. Minor eye ailments were treated and prescriptions and advice were given to appropriate cases. A local eye camp was organized for cataract operations.

\section{RESULTS}

The number of subjects who reported to us for any kind of eye complaint, except cataract, and the population, grouped by age and sex, are shown in Table 1 . The census population of the 149 villages under study was 182976 , of which $50.5 \%$ were male and $49.5 \%$ female. Among the 1195 patients examined, $56.9 \%$ were male and $43.1 \%$ female. Among the people examined with eye complaints, $14 \cdot 1 \%$ were aged $0-6$ years, $24 \cdot 4 \% 7-19$ years and $61 \cdot 4 \%$ 20 years and over. The number of female patients was significantly lower than the number of males.

The occurrence (persons/1000 population) of acute and long-standing xerophthalmia in relation to age and sex is shown in Table 2 ; only 0.03 had night blindness, 0.04 conjunctival xerosis and Bitot's spot, 0.04 corneal xerosis, 1.69 both night blindness and conjunctival xerosis with Bitot's spot and 0.06 conjunctival and corneal xerophthalmia together. The incidence of acute xerophthalmia of all kinds was $1.86 / 1000$ population. The incidence of healed keratomalacia was 0.20 persons/ 1000 . Combining all active and healed cases, 2.06 persons $/ 1000$ had xerophthalmia. The overall incidence (persons $/ 1000$ population) in males for the three age groups was $4 \cdot 71,0-6$ years; $5 \cdot 01,7-19$ years; $0.34,20$ years and over. The average for males was $2 \cdot 89$. The total incidence in females for the three age groups was 3.04 , $0-6$ years; $1 \cdot 68,7-19$ years; $0 \cdot 10,20$ years and over. The average incidence for females was 1.23. The incidences of combined xerophthalmia and corneal xerosis and healed corneal scars were, however, higher in males than in females. The overall incidence was also significantly higher in males than in females. 
Table 4. Cases by age, sex and xerophthalmia classification associated with diarrhoea

\begin{tabular}{|c|c|c|c|c|c|c|c|c|c|c|}
\hline \multirow[b]{2}{*}{ Age-group (years)... } & \multicolumn{4}{|c|}{$\sigma^{\pi}$} & \multicolumn{6}{|c|}{ q } \\
\hline & $0-6$ & $7-19$ & $20+$ & Total & $\%$ & $0-6$ & $7-19$ & $20+$ & Total & $\%$ \\
\hline $\begin{array}{l}\text { Night blindness }(\mathrm{XN}) \\
\text { with diarrhoea }(A)\end{array}$ & - & 1 & 0 & 1 & 0.44 & - & 1 & - & 1 & $1 \cdot 03$ \\
\hline $\begin{array}{l}\text { Conjunctival xerosis (XIA) } \\
\text { and Bitot's spots (XIB) } \\
\text { with diarrhoea }(B)\end{array}$ & - & 1 & - & 1 & 0.44 & - & 2 & - & 2 & $2 \cdot 06$ \\
\hline $\begin{array}{l}A+B \\
(\mathrm{XN}+\mathrm{XIA}+\mathrm{XIB})\end{array}$ & 80 & 112 & 7 & $199^{*}$ & 87.66 & 34 & 31 & - & $65^{*}$ & $67 \cdot 01$ \\
\hline $\begin{array}{l}\text { Corneal xerosis, small and } \\
\text { large active ulcer } \\
\text { (X2, X3A, X3B) } \\
\text { with diarrhoea }(C)\end{array}$ & 2 & - & - & 2 & 0.88 & 3 & 1 & - & 4 & $4 \cdot 12$ \\
\hline $\begin{array}{l}A+B+C \\
(\mathrm{XN}+\mathrm{XIA}+\mathrm{XIB}+ \\
\mathrm{X} 2, \mathrm{X} 3 \mathrm{~A}, \mathrm{X} 3 \mathrm{~B})\end{array}$ & 5 & - & - & 5 & $2 \cdot 20$ & 5 & 2 & - & 7 & $7 \cdot 21$ \\
\hline $\begin{array}{l}\text { Corneal healed scar (XS) } \\
\text { with diarrhoea }(D)\end{array}$ & 2 & 14 & 3 & 19 & $8 \cdot 37$ & 5 & 9 & 4 & 18 & $18 \cdot 55$ \\
\hline Total & 89 & 128 & 10 & 227 & & 47 & 46 & 4 & 97 & \\
\hline Rate $/ 1000$ & 0.96 & 1.38 & $0 \cdot 10$ & $2 \cdot 45$ & & 0.52 & 0.50 & 0.04 & $1 \cdot 07$ & \\
\hline
\end{tabular}

* Prevalence rates for males and females were significantly different: $P<0 \cdot 01$.

The existence of night blindness was often associated with conjunctival xerosis and Bitot's spot (Table 3). Of all night blindness and conjunctival xerosis and Bitot's spot cases only night blindness was present in $1.67 \%$ of males and $1.20 \%$ of females. Combined conjunctival xerosis and Bitot's spot was present in $1.67 \%$ of male and $3.61 \%$ of female cases. Night blindness was associated with conjunctival xerosis and Bitot's spot in $96.6 \%$ of male and $95 \cdot 2 \%$ of female patients.

Cases grouped by age, sex and WHO xerophthalmia classification associated with diarrhoea are shown in Table 4 . Of the night blindness cases, only $0.44 \%$ were associated with diarrhoea in males and $1.03 \%$ in females. Similarly, $0.44 \%$ of combined conjunctival xerosis and Bitot's spot cases were associated with diarrhoea in males and $2.06 \%$ in females. When the three conditions (XN, XIA, XIB) were present together, nearly $88 \%$ of cases were associated with diarrhoea in males and $67 \%$ in females. In the cases of combined corneal xerosis $(\mathrm{X} 2+\mathrm{X} 3 \mathrm{~A}+\mathrm{X} 3 \mathrm{~B}), 0.88 \%$ were associated with diarrhoea in males and $4 \cdot 12 \%$ in females. When all the acute xerophthalmia $(\mathrm{XN}+\mathrm{XIA}+\mathrm{XIB}+\mathrm{X} 2+\mathrm{X} 3 \mathrm{~A}+\mathrm{X} 3 \mathrm{~B})$ cases were present together, $2.21 \%$ were associated with diarrhoea in males and $7.2 \%$ in females. However, this difference was not statistically significant. Over 8.3 and $8.5 \%$ of corneal healed scar (XS) cases were associated with diarrhoea in males and females respectively. The overall association of acute and long-standing xerophthalmia with diarrhoea was $85.6 \%$ in males and $86.6 \%$ in females. The rate of association of xerophthalmia with diarrhoea was significantly higher in males than in females $(P<0.01)$.

The causes of corneal opacity grouped by age and sex are shown in Table 5 . Of all corneal opacities, $11.3 \%$ were associated with keratomalacia in males and $13.1 \%$ in females. Scars caused by trauma were $31.4 \%$ in males and $26.6 \%$ in females. Corneal infection caused a higher rate of opacity in females $(48.9 \%)$ than in males $(43.5 \%)$. Measles was responsible for $10.0 \%$ of scars in males and $7.0 \%$ in females. Smallpox caused $3.8 \%$ of opacities in males and $4.4 \%$ in females. The overall rate of corneal opacity was 2.57 persons $/ 1000$ population. Males contributed $51 \%$ and females $49 \%$ to all cases of corneal scars. 


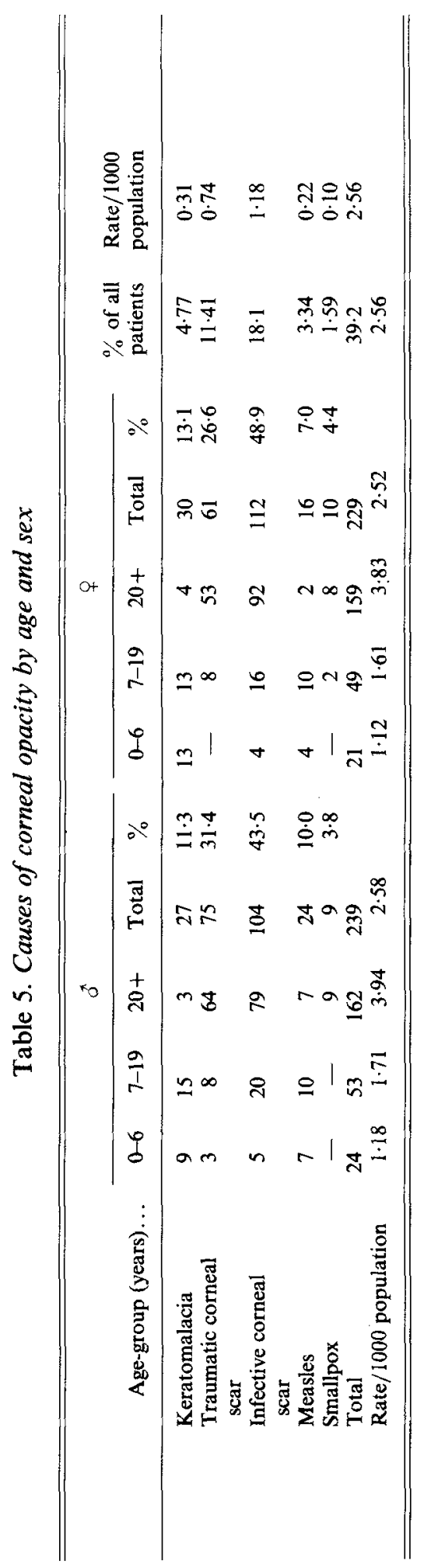




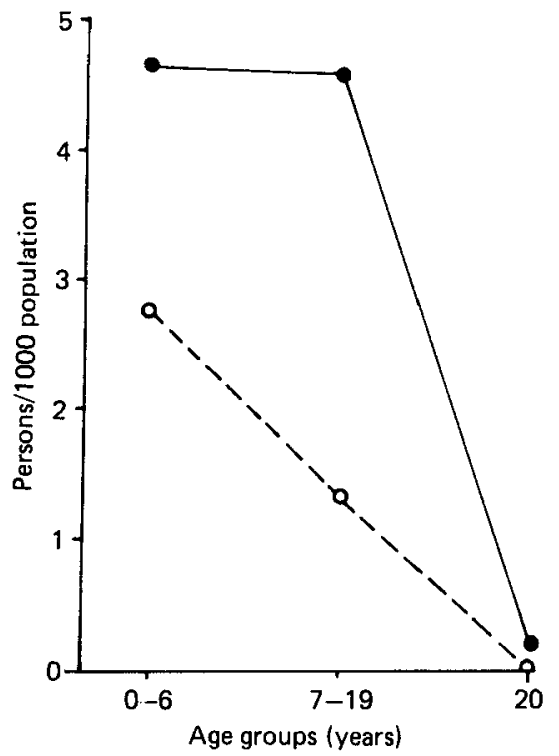

Fig. 1. Incidence of acute xerophthalmia in relation to age and sex in the population of rural Matlab, Bangladesh; (O) female, (O) male.

Fig. 1 shows the acute xerophthalmia by age and sex, as has been described in Table 2 . It is evident that acute xerophthalmia persisted up to the age of 19 years, and that there was a significant male predominance.

\section{DISCUSSION}

Although we informed every household, some mild cases may not have been reported. Many cases of early night blindness and conjunctival and corneal xerosis are not easily detected by patients or their parents. Bitot's spot, when prominent, draws the attention of parents; therefore, it is possible that only advanced cases were reported and identified. Prevalence rates might have been found to be higher, had we been able to go from door to door interviewing everyone personally. Night blindness is a well-known phenomenon with a number of local names; nevertheless, compared with a $0.4 \%$ prevalence of nutritional ocular disease in Indonesia and one of $1.7 \%$ in India, there was only a $0.15 \%$ prevalence in Bangladesh during 1973-4. Methodological differences could be partly responsible for the lower rate in the present study, which shows a $0.20 \%$ prevalence of xerophthalmia, including $0.17 \%$ night blindness, conjunctival xerosis and Bitot's spot. This low prevalence may be due, at least in part, to wide publicity (WHO/UNICEF Joint Report, 1982) and distribution by UNICEF of vitmain $A$ in the rural area after the survey, and publicity (Institute of Nutrition and Food Science, Dhaka) about the vitamin A content of local fruits and vegetables. The night blindness prevalence of $0.17 \%$, with or without association of conjunctival xerosis and Bitot's spot, is less than the previous finding of $1.5 \%$ by Rahman (1980); however, $0.2 \%$ of people in the study area had at least one ocular disease symptomatic of vitamin A deficiency. This is much less than in other developing countries. Many children in the study area with severe vitamin deficiencies, including that of vitamin A, may have died in infancy, thus giving an overall low rate. This possibility agrees with the findings of the WHO/UNICEF Joint Report (1982).

Nearly $44 \%$ of all visual defects were due to corneal opacity. A higher prevalence in the 
age group 10-39 years in males than in females might be due to their higher exposure to hazards. In Nigeria, only $20 \%$ of blindness was due to corneal opacity, despite the presence of trachoma. Interestingly, xerophthalmia $(\mathrm{XN}+\mathrm{XIA}+\mathrm{XIB}+\mathrm{X} 2+\mathrm{X} 3 \mathrm{~A}+\mathrm{X} 3 \mathrm{~B})$ was significantly higher in males than in females. There are two possible reasons: either females consume more green leafy vegetables than males, or female xerophthalmia cases are less adequately reported. The Institute of Nutrition and Food Science, University of Dhaka (1980) found that females consume more green vegetables than do males. Although night blindness cases are said to be exclusively common in children aged 2-6 years, we found that $42.5 \%$ of night blindness cases, with or without conjunctival xerosis and Bitot's spot, occurred among those aged $0-6$ years, $54 \cdot 2 \%$ in children and young adults aged $7-19$ years, and $3.3 \%$ in those 20 years or over. In other studies, only children up to the age of 6 years may have been examined (Sommer, 1981). Many older children and adolescents could have been omitted by such selection. At the same time, many childhood night blindness cases may have persisted up to adolescence due to a chronic shortage of vitamin $\mathrm{A}$ in food and to the fact that such adolescents did not get a share of vitamin A supplements, which were distributed only to children up to the age of 6 years.

Nearly $86 \%$ of xerophthalmia $(\mathrm{XN}+\mathrm{XIA}+\mathrm{XIB}+\mathrm{X} 2+\mathrm{X} 3 \mathrm{~A}+\mathrm{X} 3 \mathrm{~B})$ cases had a history of diarrhoea or dysentery during or before the onset of the eye problem. This too confirms other findings (Directorate of Nutrition, Ministry of Health, 1980; Sommer, 1981). Since diarrhoea is common in Bangladesh (Khan \& Shahidullah, 1980), we are not sure how many people with severe diarrhoea escaped ocular manifestation of vitamin A deficiency. Controlling diarrhoea may reduce xerophthalmia.

As reported elsewhere (Krishnamurty, 1980; McLaren, 1980), measles is an important causal factor in corneal opacity. Over $8.5 \%$ of corneal opacity cases in the present study had a history of measles during the onset of corneal opacity or within the previous $30 \mathrm{~d}$. However, it is not clear whether measles directly infects the cornea producing a corneal ulcer, or indirectly interferes with vitamin $\mathrm{A}$ absorption by causing diarrhoea. Further investigations are needed to explore $(a)$ why night blindess persists in adolescents; $(b)$ what protects females as opposed to males from getting night blindness and other xerophthalmia; and $(c)$ whether children with night blindness or with other xerophthalmia, or both, are more susceptible to keratomalacia, especially after diarrhoeal episodes, than are nondiarrhoeal children.

Prevention of eye problems rests in programmes of community education and health care (H. D. G. Mahler, WHO Day message, 1976, unpublished; Jelliffe, 1980).

The authors thank Dr W. B. Greenough and Dr M. M. Rahaman, for their valuable suggestions and revision of the paper, and especially Dr Donald S. McLaren for his advice in reorganizing the manuscript. Our thanks are also due to the field staff of ICDDR, B Matlab for their co-operation, and to Mrs Prabashi Mahmood for secretarial assistance.

\section{REFERENCES}

Bhar, I. S., Kasin, S., Gall, J., Pugh, R. N. H., Bradley, A. K., Moody, J. B. \& Gilles, H. M. (1982). Annals of Tropical Medicine and Parasitology 76, 243-245.

Black, R. E., Merson, M. H., Rahman, A. S. M. M., Yunus, M., Alim, A. R. M. A., Huq, I., Yolken, R. H. \& Curlin, G. T. (1980). Journal of Infectious Diseases 142, 660.

Brown, K. H., Gilman, R. H., Gaffar, A., Alamgir, S. M., Strifa, J. L., Kapikan, A. Z. \& Sack, R. B. (1981). Nutrition Research 1, 33-46.

Chowdhury, M. K., Becker, S., Razzak, A., Sarder, A. M., Sheikh, A. K. \& Chen, L. C. (1981). Scientific Report, no. 47, p. 46. Dhaka: International Centre for Diarrhoeal Disease Research.

Directorate of Nutrition, Ministry of Health (1980). Indonesia report on Nutritional Blindness Prevention Project. 
D'Souza, S. (1981). Rural Demography (Dhaka) 8(1), 29-51.

Horntino, S., Solon, B. M. P., Thomas, L. F. \& Michael, L. M. (1978). American Journal of Clinical Nutrition $3(5), 360-368$.

Institute of Nutrition and Food Science, University of Dhaka (1977). Nutrition Survey of Rural Bangladesh 1975-76. Dhaka: Institute of Nutrition and Food Science.

Institute of Nutrition and Food Science, University of Dhaka (1980). Nutrition Report (Pushti Barta): Recommendation of 1975-76 Survey, p. 108. Dhaka: Institute of Nutrition and Food Science.

Jelliffe, D. B. (1980). Journal of Tropical Pediatrics 26(4), ii.

Khan, M. \& Shahidullah, M. (1980). Transactions of the Royal Society of Tropical Medicine and Hygiene 74, 528.

Krishnamurty, K. A. (1980). In Potency and Efficiency of Vaccines [F. E. Andre, editor]. Rixensart, Belgium: Smith Kline-RIT.

McLaren, D. S. (1970). British Medical Journal ii, 668.

McLaren, D. S. (1980). Nutritional Ophthalmology. London: Academic Press.

Nigar, S. (1981). Complications of measles in rural Bangladesh (long-term complications in the under 2-year-olds). MSc in Community Health Dissertation, London School of Hygiene and Tropical Medicine.

Rahman, M. (1980). Nutrition 80(5), 10-11.

Sommer, A. (1981). Nutritional Blindness: Xerophthalmia and Keratomalacia. New York: Oxford University Press.

Sommer, A., Hussaini, G., Sugana, T., Nani, E. \& Tarwotjo, I. (1978). Praceedings of the XXIIIrd International Congress of Ophthalmology, pp. 1615-1618. Amsterdam: Excerpta Medica.

Sommer, A., Hussaini, G., Muhilal, Tarwotjo, I., Susanto, D. \& Saroso, J. S. (1980). American Journal of Clinical Nutrition 33, 887-891.

Sommer, A., Tarwotjo, I., Hussaini, G., Susanto, D. \& Soegiharto, T. (1981). Lancet i, 1407-1408.

Swaminathan, M. C., Susheela, T. P. \& Thimmayamma, B. V. S. (1970). American Journal of Clinical Nutrition 23, 119-122.

WHO/UNICEF Joint Report (1982). Control of Vitamin A Deficiency and Xerophthalmia. Technical Report Series no. 672. Geneva: WHO.

WHO/USAID Joint Report (1976). Vitamin A Deficiency and Xerophthalmia. Technical Report Series no. 590. Geneva: WHO. 